\title{
Valorization of Tunisian secondary date varieties (Phoenix dactylifera L.) by hydrothermal treatments: New fiber concentrates with antioxidant properties
}

\author{
Abdessalem Mrabet ${ }^{\mathrm{a}, \mathrm{c}}$, Guillermo Rodríguez-Gutiérrez ${ }^{\mathrm{a}}$, Rafael Guillén-Bejarano ${ }^{\mathrm{a}}$, \\ Rocío Rodríguez-Arcos ${ }^{a}$, Ali Ferchichi ${ }^{b}$, Marianne Sindic ${ }^{c}$, Ana Jiménez-Araujo ${ }^{\text {a, * }}$ \\ ${ }^{a}$ Instituto de la Grasa, Consejo Superior de Investigaciones Científicas (CSIC), Avda. Padre García Tejero ${ }^{\circ}$ 4, Sevilla 41012, Spain \\ ${ }^{\mathrm{b}}$ Arid and Oases Cropping Laboratory, Arid Area Institute, Medenine 4119, Tunisia \\ c University of Liege - Gembloux Agro-Bio Tech., Department of Food Technol., Passage des Déportés, 2, B-5030 Gembloux, Belgium
}

\section{A R T I C L E I N F O}

\section{Article history:}

Received 17 September 2013

Received in revised form

10 January 2014

Accepted 22 September 2014

Available online 2 October 2014

\section{Keywords:}

Secondary date varieties

Hydrothermal treatment

Fiber concentrates

Chemical composition

Antioxidant activity

\begin{abstract}
A B S T R A C T
Two hydrothermal treatments were assayed on secondary date varieties from the Tunisian coastal oasis in order to obtain valuable solid extracts, rich in dietary fiber and antioxidants. The steam explosion treatment (SET) is based on high temperatures and pressures, with an explosive decompression. The steam treatment (ST), without rapid decompression, has lower pressures and temperatures, but longer treatments than SET. The recovery of the fiber concentrates (FCs) was very similar for the different assayed conditions. Only its granulometry showed differences, increasing the fraction with size lower than $4 \mathrm{~mm}$ in more intense treatments. Treatment conditions had higher influence than date variety in the FCs chemical composition. It was approximately $0.1-2 \%$ soluble sugar, $0.7-2 \%$ uronic acids, $4-8 \%$ phenols, $5-11 \%$ fat, $5-22 \%$ non-cellulosic sugars, $9-14 \%$ protein, $12-20 \%$ cellulose, and $44-71 \%$ lignin, depending on treatment conditions. They had also very high antiradical activity (230-580 mmols Trolox/ $\mathrm{Kg} \mathrm{FC}$ ). The use of ST reactor is highly recommended because it could be easily scaled up to the industry. The FC obtained by hydrothermal treatments from date fruits could be considered as a very interesting ingredient for healthier food, especially for bakery or dairy products due to its pleasant chocolate/coffee flavor.
\end{abstract}

() 2014 Elsevier Ltd. All rights reserved.

\section{Introduction}

The fruits of the date palm (Phoenix dactylifera L.) are commonly consumed in many parts of the world and a vital component of the diet and a staple food in most of Arabic countries. Dates are one of the main crops in Tunisia and represent a major source of income for the majority of the population in the rural areas. They are also important for the ecology of the country, being the most adaptive crop and tolerant to various environmental stresses (Al-Farsi, 2003). Tunisia is considered to be one of the most important producers for Deglé Nour, cultivar with very good sensory quality and a

Abbreviations: SET, steam explosion treatment; ST, steam treatment; DPPH, 2,2diphenyl-1-picrylhydrazyl free radical; FC, fiber concentrate; NCS, non-cellulosic sugars; TFA, trifluoroacetic acid; EC, efficient concentration; TE, Trolox equivalents; WHC, water holding capacity; SOL, solubility; OHC, oil holding capacity.

* Corresponding author. Instituto de la Grasa, CSIC, Avda. Padre García Tejero n ${ }^{\circ} 4$, Sevilla-41012, Spain. Tel: +34 954692516; fax: +34 954691262

E-mail address: araujo@cica.es (A. Jiménez-Araujo). high commercial value. This production is unfortunately accompanied by a decrease of cultivars characterized by a low commercial quality (secondary cultivars). They are less appreciated and account for approximately $30 \%$ of Tunisian dates (Chibane, Benamara, Noui, \& Djouad, 2007). Although they are not used as human food, they are rich in many bioactive compounds (Elleuch et al., 2008).

Limited data are available regarding the compositional and functional characteristics of secondary dates grown in Tunisia (Elleuch et al., 2008; Mrabet et al., 2012). Attempts should be made to convert these unused varieties into value added products in order to increase the economic feasibility of date industries. Recently, Mrabet et al. (2012) concluded that some of these varieties could be valuable as a source of antioxidant dietary fiber, but pre-treatment could be necessary for the total utilization of the dates. One of the more interesting processes is based on hydrothermal pretreatments that allow for the extraction of soluble compounds to the liquid phase, leaving a fibrous material as solid fraction (Fernández-Bolaños et al., 2004). Among the existing methods, steam explosion treatment (SET) is one of the most commonly used 
for fractionation of biomass components. The SET technique is very useful for the separation of cellulose, hemicellulose and lignin from raw materials, as wheat straw (Montane, Farriol, \& Salvado, 1998), bagasse (Kar, Gutiérrez, \& Kinoshita, 1998), and olive stone (Fernandez-Bolaños et al., 2001). As pressures for SET are very high for usual industrial steam generators $\left(42 \mathrm{~kg} / \mathrm{cm}^{2}\right)$, another pretreatment has been developed (Lama-Muñoz, Rodríguez-Gutiérrez, Rubio-Senent, Gómez-Carretero, \& Fernández-Bolaños, 2011). The new one is also based on steam treatment (ST) but without explosive decompression, working at lower pressure $\left(9 \mathrm{~kg} / \mathrm{cm}^{2}\right)$ with longer treatments.

The objective of this study was to apply for the first time both thermal pretreatment systems based on steam technology to secondary date varieties from Tunisia, in order to evaluate the chemical composition, functional properties and antioxidant activity of fiber concentrates obtained from the solid fraction. With this information, an industrial treatment could be proposed to valorize these cultivars so important from economical and social points of view.

\section{Materials and methods}

\subsection{Chemicals}

Trifluoroacetic acid (TFA), 3-phenylphenol, anthrone, Folin-Ciocalteu phenol reagent, and 2,2-diphenyl-1-picrylhydrazyl (DPPH• free radical) were purchased from Sigma-Aldrich Química (Madrid, Spain). $\mathrm{Na}_{2} \mathrm{CO}_{3}$, hexane, sodium hydroxide, and acetic acid were from Panreac Química S.A. (Barcelona, Spain). Standards of gallic acid and myoinositol were purchased from Sigma-Aldrich Química. Ethyl acetate and acetonitrile were of HPLC grade purity (Romyl, Teknokroma, Barcelona, Spain). Sulfuric acid and acetone were from Sharlau (Barcelona, Spain). Ethanol was purchased from Alcoholes del Sur (Córdoba, Spain).

\subsection{Plant material}

Three secondary date varieties (Eguwa, Garen Gaze, and Smeti) at the "Tamr stage" (full ripeness) were studied. These varieties were chosen due to their high values of antioxidant activity linked to dietary fiber, as previously reported (Mrabet et al., 2012). They were picked at Gabès littoral oasis (southern Tunisia) during the 2011 harvest season (September-October). All samples were stored at $-20{ }^{\circ} \mathrm{C}$ until analysis and treatment.

\subsection{Thermal treatments}

Prior to both treatments fruits were cut longitudinally to improve the access of steam to the date seed. SET was carried out using a 2-L capacity reactor (Fig. 1, Subfig. A). Date samples (250 g) of each variety were treated with a saturated steam at a maximum operating pressure of $42 \mathrm{~kg} / \mathrm{cm}^{2}$. The reactor was equipped with a quick-opening ball valve and an electronic device programmed for the accurate control of steam time and temperature for the final steam explosion. After the treatment, the samples were collected, vacuum filtered through filter paper, and freeze-dried. ST, without explosion, was carried out using a 100-L capacity reactor (Fig. 1, Subfig. B), which can operate at temperatures between 50 and $190{ }^{\circ} \mathrm{C}$ by direct heating, and at a maximum pressure of $9 \mathrm{~kg} / \mathrm{cm}^{2}$. The system allows for the appropriate treatment of dates without explosion or high pressures and temperatures. In this case, date samples consisted of a variety blending. The wet treated material was filtered by centrifugation at $4700 \mathrm{~g}$ (Comteifa, S.L., Barcelona, Spain) and freeze-dried.

In both treatments, seed pieces higher than $4 \mathrm{~mm}$ were removed from the dried solid fractions by sieving. The material under $4 \mathrm{~mm}$ was considered the fiber concentrate (FC) to be characterized in the present work.

\subsection{Ethanol extraction of date samples and FCS}

One gram of date flesh, seed or FC was extracted twice with $100 \mathrm{~mL}$ of $80 \%$ ethanol. After filtration, both liquors were collected and made up to $200 \mathrm{~mL}$ in a volumetric flask. In these extracts, soluble sugars, total phenols and soluble antiradical activity were determined.

\subsection{Proximate composition}

For date flesh, all the determinations were carried out from soluble sugar-free material ( $80 \%$ ethanol extracted). Date seeds and FCs were directly analyzed.

Protein content was determined by the Kjeldahl method and applying a factor of 6.25 to convert the total nitrogen into protein content. Soluble sugars were determined using the anthrone method. Klason lignin levels were determined gravimetrically as the acid-insoluble material remaining after a two-stage sulfuric acid hydrolysis. The fat was quantified with hexane using a Soxhlet apparatus. Uronic acids were quantified using the phenyl-phenol
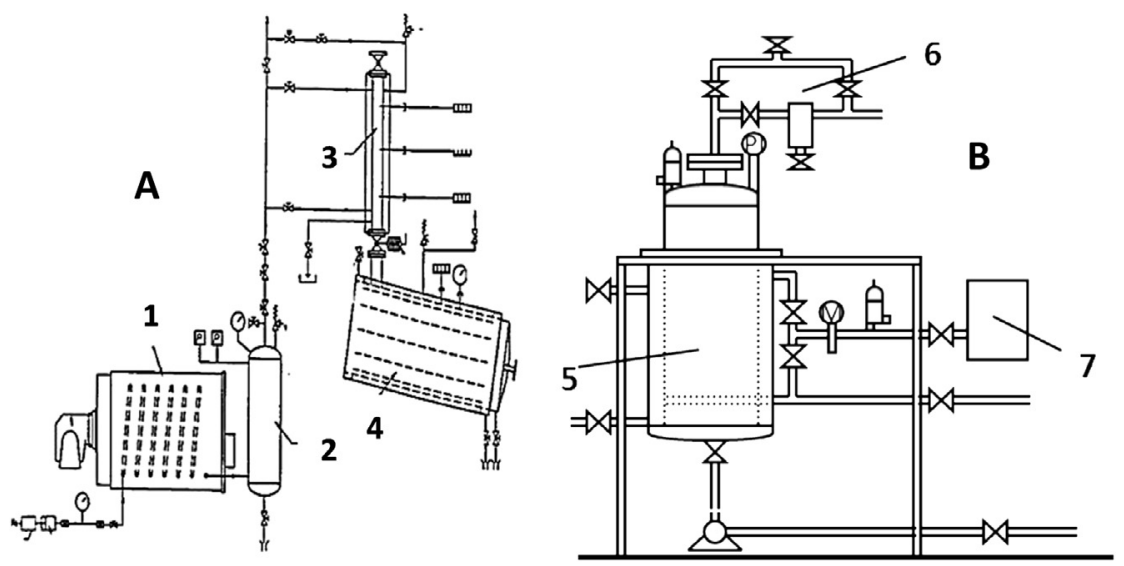

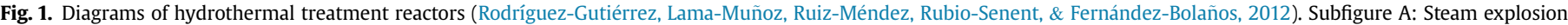

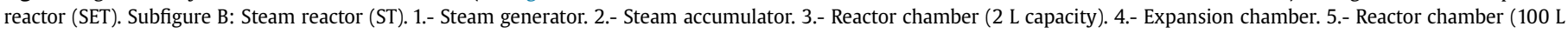
capacity). 6.- Cooler. 7.- Steam accumulator. 
method after sulfuric acid hydrolysis. Cellulose was quantified from the TFA-insoluble residue after sulfuric acid hydrolysis by the anthrone method. Non-cellulosic sugar (NCS) composition was determined by hydrolysis with $2 \mathrm{~N}$ TFA at $121{ }^{\circ} \mathrm{C}$ for $1 \mathrm{~h}$. The released sugars were quantified as alditol acetates by gas chromatography.

The total polyphenol content was quantified for each ethanol extract according to the Folin- Ciocalteu spectrophotometric method, using gallic acid as a reference standard compound. The total phenolic content of the samples was expressed as gallic acid equivalents $(\mathrm{g} / 100 \mathrm{~g})$.

\subsection{Determination of the antiradical activity}

Soluble antiradical activity was determined from the ethanol extracts by the DPPH• method (Rodríguez et al., 2005). The efficient concentration $\mathrm{EC}_{50}$, which represents the amount of antioxidant necessary to decrease the initial absorbance by $50 \%$, was calculated from a calibration curve by linear regression for each sample.

The antiradical activity of the insoluble residue after ethanol extraction was evaluated as described by Fuentes-Alventosa et al. (2009). As for soluble antiradical activity, $\mathrm{EC}_{50}$ was also calculated. Both activities were expressed as millimoles of Trolox equivalent (TE) antioxidant capacity per kilogram of sample by means of a dose-response curve for Trolox.

\subsection{Water-and oil-holding capacity, and solubility}

Water-holding capacity (WHC) and oil-holding capacity (OHC) were determined using the method described by Jiménez et al. (2000). Samples $(250 \mathrm{mg} \times 3)$ were suspended in $15 \mathrm{~mL}$ of water or sunflower oil ( $1.0054 \mathrm{~g} / \mathrm{mL}$ density), respectively. After $24 \mathrm{~h}$ of stirring at room temperature the suspension was centrifuged at $14000 \mathrm{~g}$ for $1 \mathrm{~h}$. Supernatants were carefully eliminated, and the pellets were weighed. From WHC samples, hydrated pellets were freeze-dried, and their solubility in water (SOL) was determined by the difference in weight before and after the WHC assay, which was expressed as a percentage.

\subsection{Statistical analysis}

The results are expressed as the average value of at least three repetitions. To assess the differences in composition, functional characteristics and antiradical activity among samples, a multiplesample comparison was performed using the Statgraphics Plus program Version 2.1. Multivariate analysis of variance (ANOVA), followed by Duncan's multiple comparison test, was performed to differentiate the groups. The level of significance was $P<0.05$.

\section{Results and discussion}

\subsection{Chemical composition of date fruits}

Prior to hydrothermal treatments, the chemical composition of date fruits from the three varieties was studied. Flesh and seeds were analyzed separately (Table 1). Garen Gaze and Eguwa did not show significant differences in weight but did in flesh/seed ratio. Smeti dates were bigger and with a higher flesh/seed ratio. Only moisture and soluble sugars were present in higher amounts in the flesh than in the seed. Moisture was twice as high in the flesh, varying significantly from 23\% in Garen Gaze to 31\% in Smeti. Soluble sugars were higher than $60 \%$ in the flesh and around $1 \%$ in the seed, and they did not show significant differences among varieties. Lignin was the second component in quantity (23-27\%) in the flesh and, as was the case for NCS, there were not any statistical differences among varieties. These high percentages could be related to the inedibility of these varieties, as proposed previously (Mrabet et al., 2012). The rest of the components were lower than $10 \%$, with remarkably low amounts of fat $(0.3-0.5 \%)$ and phenols (0.04-0.07\%). Phenols and antiradical activity were in the same range as previously described (Mrabet et al., 2012).

The NCS composition was also studied in the flesh and seeds. In Fig. 2, Subfig. A, the results for Garen Gaze are presented (Eguwa and Smeti did not show differences with Garen Gaze). In the flesh, glucose was the main sugar (higher than $70 \%$ ), followed by xylose (12\%). The other sugars were lower than $10 \%$. In the seed, mannose was the major sugar (near 60\%) and afterwards glucose (around 30\%). A glucomannan has been described from the seeds of Libyan dates (Ishrud, Zahid, Ahmad, \& Pan, 2001). After hydrolysis, this polysaccharide gave mannose, glucose, arabinose, and galactose in the ratio 55:23:10:10, a very similar composition to that presented in Fig. 2, Subfig. A.

The percentage of fat (13-17\%) and phenols (1-5\%) present in date seeds were of great interest. Due to these amounts of phenols, the antiradical activity of seeds was much higher (131-400 mmol TE/Kg dry weight) than that of the flesh

Table 1

Chemical composition (\%) and antiradical capacity (mmol TE/Kg) of date varieties.

\begin{tabular}{|c|c|c|c|c|c|c|c|c|c|}
\hline \multirow[b]{2}{*}{ Weight/fruit (g) } & \multicolumn{3}{|l|}{ GG } & \multicolumn{3}{|l|}{ EG } & \multicolumn{3}{|l|}{ SM } \\
\hline & \multicolumn{3}{|l|}{$6.99 \pm 0.97 a$} & \multicolumn{3}{|l|}{$7.74 \pm 1.05 \mathrm{a}$} & \multicolumn{3}{|l|}{$11.49 \pm 0.74 b$} \\
\hline \multirow[t]{2}{*}{ Flesh/seed ratio } & \multicolumn{3}{|l|}{$5.93 \pm 1.02 \mathrm{~b}$} & \multicolumn{3}{|l|}{$5.02 \pm 0.74 \mathrm{a}$} & \multicolumn{3}{|l|}{$8.17 \pm 1.28 c$} \\
\hline & Flesh & & Seed & Flesh & & Seed & Flesh & & Seed \\
\hline Moisture & $22.98 \pm 2.64 b$ & & $11.63 \pm 1.17 \mathrm{a}$ & $26.67 \pm 0.99 c$ & & $13.34 \pm 0.67 \mathrm{a}$ & $31.47 \pm 1.25 \mathrm{~d}$ & & $12.93 \pm 0.46 \mathrm{a}$ \\
\hline Soluble sugars ${ }^{\mathrm{a}}$ & $61.61 \pm 4.92 b$ & & $0.26 \pm 0.00 \mathrm{a}$ & $62.01 \pm 5.05 b$ & & $1.50 \pm 0.01 \mathrm{a}$ & $60.64 \pm 3.86 b$ & & $0.58 \pm 0.01 \mathrm{a}$ \\
\hline Lignin $^{\mathrm{a}}$ & $25.15 \pm 0.92 c$ & $66.98^{\mathrm{b}}$ & $25.44 \pm 0.06 c$ & $27.5 \pm 0.71 \mathrm{c}$ & 72.39 & $19.60 \pm 0.85 a$ & $23.75 \pm 2.54 b c$ & 60.34 & $23.20 \pm 0.56 \mathrm{bc}$ \\
\hline $\mathrm{NCS}^{\mathrm{a}}$ & $6.96 \pm 0.54 \mathrm{a}$ & 18.53 & $20.55 \pm 2.06 \mathrm{~d}$ & $7.24 \pm 0.26 a$ & 19.06 & $19.73 \pm 0.89 c$ & $7.73 \pm 0.63 \mathrm{a}$ & 19.64 & $10.84 \pm 0.69 b$ \\
\hline Cellulose $^{a}$ & $1.58 \pm 0.21 \mathrm{a}$ & 4.21 & $20.28 \pm 1.37 c$ & $1.72 \pm 0.15 a$ & 4.53 & $17.04 \pm 0.94 b$ & $1.74 \pm 0.23 \mathrm{a}$ & 4.42 & $17.79 \pm 1.28 b$ \\
\hline Protein $^{a}$ & $1.70 \pm 0.10 a$ & 4.53 & $5.88 \pm 0.04 \mathrm{~d}$ & $1.61 \pm 0.05 a$ & 4.27 & $4.64 \pm 0.20 c$ & $2.33 \pm 0.07 b$ & 5.92 & $5.79 \pm 0.36 \mathrm{~d}$ \\
\hline Uronic $_{\text {acids }}{ }^{\mathrm{a}}$ & $1.60 \pm 0.21 \mathrm{a}$ & 4.26 & $4.03 \pm 0.33 \mathrm{~d}$ & $1.36 \pm 0.11 \mathrm{a}$ & 3.58 & $4.57 \pm 0.43 \mathrm{e}$ & $2.28 \pm 0.21 b$ & 5.79 & $2.60 \pm 0.22 c$ \\
\hline Fat $^{\mathrm{a}}$ & $0.52 \pm 0.01 \mathrm{a}$ & 1.38 & $17.53 \pm 0.71 c$ & $0.35 \pm 0.01 \mathrm{a}$ & 0.92 & $17.75 \pm 1.41 \mathrm{c}$ & $0.44 \pm 0.02 \mathrm{a}$ & 1.12 & $13.54 \pm 0.71 \mathrm{~b} \mathrm{~b}$ \\
\hline Phenols ${ }^{\mathrm{a}}$ & $0.04 \pm 0.00 \mathrm{a}$ & 0.11 & $1.05 \pm 0.03 b$ & $0.07 \pm 0.00 \mathrm{a}$ & 0.18 & $5.72 \pm 0.27 \mathrm{~d}$ & $0.04 \pm 0.00 \mathrm{a}$ & 0.10 & $4.24 \pm 0.13 c$ \\
\hline Antiradical activity ${ }^{\mathrm{a}, \mathrm{c}}$ & $47.75 \pm 0.09 \mathrm{~b}$ & & $131.30 \pm 6.56 \mathrm{c}$ & $38.58 \pm 0.06 \mathrm{ab}$ & & $400.40 \pm 36.03 \mathrm{e}$ & $32.67 \pm 0.12 \mathrm{a}$ & & $320.20 \pm 28.82 \mathrm{~d}$ \\
\hline
\end{tabular}

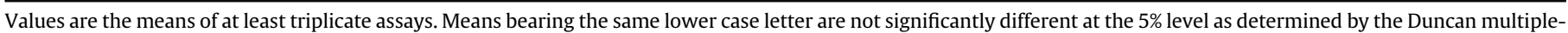
range test.

TE.- Trolox equivalent. GG.- Garen Gaze. EG.- Eguwa. SM.- Smeti. NCS.- non cellulosic sugars.

a Expressed as dry weight basis.

b Results in italics are expressed as dry and soluble sugar-free weight basis.

c Total antiradical activity, as a sum of soluble and insoluble activities. 

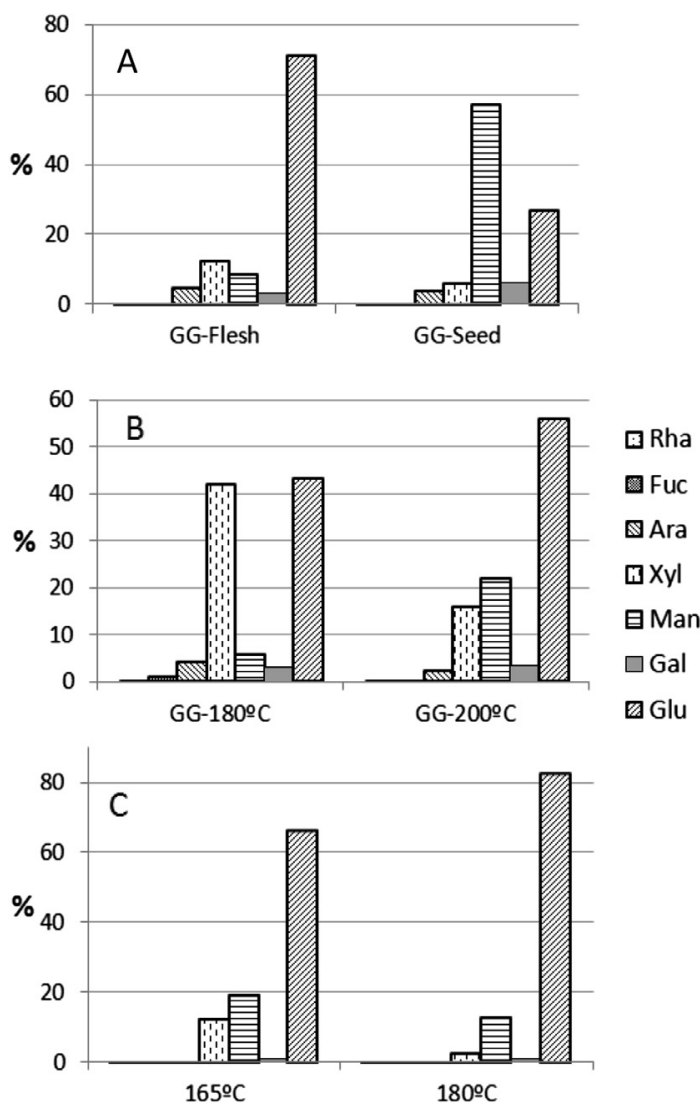

Fig. 2. Glycosyl composition, expressed as relative percentages, of fresh Garen Gaze dates (flesh and seed) and FCs after hydrothermal treatments. Subfigure A: Fresh Garen Gaze dates. Subfigure B: Garen Gaze variety, SET reactor. Subfigure C: mixed varieties, ST reactor. GG.- Garen Gaze variety. Rha.- Rhamnose. Fuc.- Fucose. Ara.- Arabinose. Xyl.- Xylose. Man.- Mannose. Gal.- Galactose. Glu.- Glucose.

(32-47 mmol TE/Kg dry weight), as described by other authors (Nehdi, Oruri, Khalil, \& Al-Resayes, 2010). Although the seed is the minor and inedible portion of date fruits, its composition is very important in this study because during hydrothermal treatments, seeds would be partially disorganized and their components could modify the composition of final products to a great extent.

\subsection{Hydrothermal treatments and overall recovery}

As explained in Materials and Methods, two different hydrothermal treatments were applied to date samples. SET (Fig. 1, Subfig. 1) has a rapid decompression (explosion) which helps in lignocellulosic material disorganization and solubilization. ST (Fig. 1, Subfig. 2) operates at lower pressures, with longer time of treatment and without explosion. The latter could be more easily applied to the industry due to its lower work pressure, having similar results to the first one when working with non pure lignocellulosic materials.

With SET, the varieties were studied separately in $250 \mathrm{~g}(\times 2)$ fresh weight samples (Table 2 ). The overall recovery was similar between duplicates and among the different treatments and varieties. Only Smeti showed little difference in duplicates at $180{ }^{\circ} \mathrm{C}$. The average recovery of dry solid residue was $25.06 \%$. This percentage seemed to be low when compared with other products, such as olive stones, treated in the same reactor where the recovery average was 59.12\% (Fernandez-Bolaños et al., 2001). It is important to take into account that soluble sugars accounted for more than $50 \%$ of date flesh dry weight (Table 1 ). If the percentages of recovery
Table 2

Conditions of hydrothermal treatments and recovery of the dry solid residue and its granulometry.

\begin{tabular}{ccccccc}
\hline & & & $\begin{array}{l}\text { Fruit dry } \\
\text { weight }(\mathrm{g})\end{array}$ & \% Recovery & $\begin{array}{l}\%<4 \\
\mathrm{~mm}^{\mathrm{a}}(\mathrm{FC})^{\mathrm{b}}\end{array}$ & $\%>4 \mathrm{~mm}^{\mathrm{a}}$ \\
\hline GG & $180{ }^{\circ} \mathrm{C}, 5^{\prime} \mathrm{SET}$ & 1 & 198.49 & 23.44 & 36.07 & 63.93 \\
& & 2 & 200.47 & 25.03 & 38.54 & 61.46 \\
& $200{ }^{\circ} \mathrm{C}, 5^{\prime} \mathrm{SET}$ & 1 & 199.19 & 25.43 & 58.39 & 41.61 \\
& & 2 & 199.94 & 25.62 & 59.18 & 40.82 \\
$\mathrm{EG}$ & $180{ }^{\circ} \mathrm{C}, 5^{\prime} \mathrm{SET}$ & 1 & 189.16 & 28.04 & 50.89 & 49.11 \\
& & 2 & 189.18 & 26.77 & 32.03 & 67.97 \\
& $200{ }^{\circ} \mathrm{C}, 5^{\prime} \mathrm{SET}$ & 1 & 189.16 & 25.41 & 53.24 & 46.76 \\
& & 2 & 189.21 & 24.08 & 45.84 & 54.16 \\
$\mathrm{SM}$ & $180^{\circ} \mathrm{C}, 5^{\prime} \mathrm{SET}$ & 1 & 176.37 & 26.84 & 48.63 & 51.37 \\
& & 2 & 176.77 & 19.93 & 47.95 & 52.05 \\
& $200{ }^{\circ} \mathrm{C}, 5^{\prime} \mathrm{SET}$ & 1 & 176.67 & 24.83 & 59.71 & 40.29 \\
& & 2 & 176.80 & 25.38 & 58.06 & 41.94 \\
$165{ }^{\circ} \mathrm{C}, 30^{\prime} \mathrm{ST}$ & & 2959.34 & 26.35 & 29.65 & 70.34 \\
$180{ }^{\circ} \mathrm{C}, 30^{\prime} \mathrm{ST}$ & & 4682.50 & 23.24 & 55.00 & 45.00 \\
\hline
\end{tabular}

GG.- Garen Gaze. EG.- Eguwa. SM.- Smeti. SET.- Steam explosion treatment. ST.Steam treatment.

a This percentage is expressed on total recovered solid residue basis.

b These fractions constituted the analyzed fiber concentrates (FC).

were calculated on the dry and soluble sugar-free basis, they would increase to $50-60 \%$, similar to those reported previously by Fernandez-Bolaños et al. (2001) for olive stones and by Garrote, Cruz, Domínguez, and Parajó (2008) for barley husks.

Although treatments at different temperatures did not lead to different recoveries in SET, this factor influenced the granulometry of recovered solid. In Garen Gaze, the increase in temperature from $180{ }^{\circ} \mathrm{C}$ to $200{ }^{\circ} \mathrm{C}$ brought about a rise in the percentage of material $<4 \mathrm{~mm}$ from $37 \%$ to $58 \%$ (average values of duplicate experiences). The same results were found on Smeti, changing from $48 \%$ to $58 \%$. Although the duplicates had high variability in Eguwa, the average values showed the same behavior as the other varieties $(41 \%$ for $180{ }^{\circ} \mathrm{C}$ and $49 \%$ for $200{ }^{\circ} \mathrm{C}$ ).

In the ST reactor the same results were found: higher treatment temperature did not lead to a different recovery, but affected the granulometry. The treatment at $180{ }^{\circ} \mathrm{C}$ almost doubled the percentage of solid $<4 \mathrm{~mm}$. Comparing both reactors, seed fragments higher than $4 \mathrm{~mm}$ from the SET had a hardness similar to those of the fresh seed, but those from the ST could be broken by finger press. This could be a technological advantage because a milder milling process would be needed for improving their granulometry for other industrial uses.

\subsection{Chemical composition of FCS}

In Table 3, the chemical composition of FCs is shown. For SET, the presented data for each treatment was the average value of the duplicates. After treatments, lignin was the major component, followed by cellulose, NCS and protein (in some cases, protein was more abundant than NCS). Fat and phenols were in similar amounts, and uronic acids and soluble sugars were the lowest, and not present in some samples. FCs obtained by ST had similar composition to those from SET, showing significant increases in lignin and uronic acids, and decreases in NCS and phenols. In order to compare the composition of FCs with that of the original date fruit, comparisons should be made on a soluble sugar-free basis. So, from the insoluble part of the flesh, lignin represented around $60.3-72.4 \%$, NCS $18.5-19.6 \%$, cellulose $4.2-4.5 \%$, protein $4.3-5.9 \%$, uronic acids $3.6-5.8 \%$, fat $0.9-1.4 \%$, and phenols $0.1-0.2 \%$, depending on date variety (columns in italics in Table 1). Compared with these percentages, the average composition of FCs (Table 3) 
Table 3

Chemical composition (\%) of FCs after hydrothermal treatments, expressed as \% on dry weight basis.

\begin{tabular}{|c|c|c|c|c|c|c|c|c|c|}
\hline & & Lignin & Cellulose & NCS & Protein & Fat & Phenols & Soluble sugars & Uronic acids \\
\hline \multirow[t]{2}{*}{ GG } & $180^{\circ} \mathrm{C}, 5^{\prime} \mathrm{SET}$ & $50.38 \pm 2.41 \mathrm{ab}$ & $14.36 \pm 1.22 \mathrm{a}$ & $16.59 \pm 1.62 b$ & $13.60 \pm 0.46 b$ & $7.19 \pm 0.69 b$ & $4.38 \pm 0.01 \mathrm{a}$ & $1.77 \pm 0.46 b$ & $0.84 \pm 0.00 \mathrm{a}$ \\
\hline & $200^{\circ} \mathrm{C}, 5^{\prime} \mathrm{SET}$ & $60.80 \pm 1.00 \mathrm{~cd}$ & $16.34 \pm 5.03 \mathrm{a}$ & $10.53 \pm 0.42 a$ & $9.31 \pm 1.31 \mathrm{a}$ & $7.74 \pm 0.20 \mathrm{~b}$ & $7.43 \pm 0.17 b$ & $1.21 \pm 0.39 b$ & $\operatorname{tr}$ \\
\hline \multirow[t]{2}{*}{ EG } & $180^{\circ} \mathrm{C}, 5^{\prime} \mathrm{SET}$ & $53.57 \pm 0.07 b c$ & $17.45 \pm 1.61 \mathrm{a}$ & $13.75 \pm 0.20 b$ & $12.84 \pm 0.48 b$ & $4.93 \pm 0.11 \mathrm{a}$ & $5.09 \pm 0.74 a$ & $0.07 \pm 0.01 \mathrm{a}$ & $1.64 \pm 0.16 b$ \\
\hline & $200^{\circ} \mathrm{C}, 5^{\prime} \mathrm{SET}$ & $63.07 \pm 2.22 \mathrm{~d}$ & $15.36 \pm 1.77 \mathrm{a}$ & $8.92 \pm 0.07 \mathrm{a}$ & $11.45 \pm 0.31 \mathrm{ab}$ & $5.61 \pm 0.24 \mathrm{ab}$ & $7.82 \pm 0.26 b$ & $1.89 \pm 0.17 b$ & $0.76 \pm 0.02 a$ \\
\hline \multirow[t]{2}{*}{ SM } & $180^{\circ} \mathrm{C}, 5^{\prime} \mathrm{SET}$ & $44.02 \pm 4.29 a$ & $17.84 \pm 1.96 a$ & $21.77 \pm 3.22 \mathrm{c}$ & $13.06 \pm 1.71 b$ & $6.80 \pm 0.39 a b$ & $4.24 \pm 0.27 \mathrm{a}$ & $2.01 \pm 0.37 b$ & $0.70 \pm 0.22 \mathrm{a}$ \\
\hline & $200^{\circ} \mathrm{C}, 5^{\prime} \mathrm{SET}$ & $58.25 \pm 1.50 \mathrm{bcd}$ & $19.77 \pm 1.18 \mathrm{a}$ & $9.66 \pm 0.12 \mathrm{a}$ & $13.28 \pm 0.39 b$ & $10.92 \pm 1.35 c$ & $7.40 \pm 0.08 b$ & $0.08 \pm 0.01 \mathrm{a}$ & $\operatorname{tr}$ \\
\hline \multicolumn{2}{|c|}{ Average } & $55.02^{*}$ & $16.86^{*}$ & $13.54^{*}$ & $12.26^{*}$ & $7.20^{*}$ & $6.06^{*}$ & $1.17^{*}$ & $0.68^{*}$ \\
\hline \multirow{3}{*}{\multicolumn{2}{|c|}{$\begin{array}{l}165^{\circ} \mathrm{C}, 30^{\prime} \mathrm{ST} \\
180^{\circ} \mathrm{C}, 30^{\prime} \mathrm{ST} \\
\text { Average }\end{array}$}} & $59.72 \pm 0.31 \mathrm{~A}$ & $18.08 \pm 1.97 \mathrm{~A}$ & $9.99 \pm 0.09 \mathrm{~A}$ & $11.41 \pm 0.85 \mathrm{~A}$ & $6.77 \pm 0.56 \mathrm{~A}$ & $4.24 \pm 0.18 \mathrm{~A}$ & $1.25 \pm 0.22 \mathrm{~A}$ & $2.05 \pm 0.20 \mathrm{~A}$ \\
\hline & & $70.98 \pm 0.92 \mathrm{~B}$ & $12.36 \pm 0.79 \mathrm{~B}$ & $4.86 \pm 0.04 \mathrm{~B}$ & $9.63 \pm 0.37 \mathrm{~A}$ & $6.09 \pm 0.60 \mathrm{~A}$ & $3.91 \pm 0.42 \mathrm{~A}$ & $0.89 \pm 0.08 \mathrm{~A}$ & $1.18 \pm 0.35 \mathrm{~B}$ \\
\hline & & $65.25^{* *}$ & $15.22^{*}$ & $7.42^{* *}$ & $10.52^{*}$ & $6.43^{*}$ & $4.08^{* *}$ & $1.07^{*}$ & $1.55^{* *}$ \\
\hline
\end{tabular}

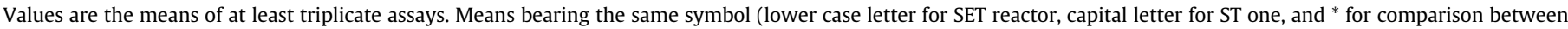
reactors) are not significantly different at the $5 \%$ level as determined by the Duncan multiple-range test.

FC.- Fiber concentrate. GG.- Garen Gaze. EG.- Eguwa. SM.- Smeti. tr.- traces. SET.- Steam explosion treatment. ST.- Steam treatment. NCS.- non cellulosic sugars.

from both reactors showed enrichment in fat, protein, cellulose and phenols in all treatments.

The date variety and the treatment lead to significant differences in some components. The SET reactor was especially designed to increase accessibility and separate the main components of lignocellulosic biomass (cellulose, hemicellulose, and lignin). In FCs obtained by SET, the content in lignin was lower than that of original fruits (if compared with data corrected without soluble sugars - columns in italic in Table 1), showing a partial solubilization of this component into the liquid fraction. In fact, some derivatives from lignin alcohols were found in treatment liquids (unpublished results). There were significant increases in lignin at $200{ }^{\circ} \mathrm{C}$. This fact could be probably due to a higher degree of seed hydrolysis at this temperature. As it was commented above, a decrease about $10-20 \%$ was quantified at $200{ }^{\circ} \mathrm{C}$ in the fraction of seed pieces $>4 \mathrm{~mm}$ (Table 2 ). Seeds were also very rich in lignin (20-25\% in dry weight basis, Table 1); therefore, an increase of seed percentages in FCs could imply higher amounts of lignin in FC composition. Besides, repolymerization of lignin and/or its reaction with other compounds (probably derived from sugar-decomposition reactions) could also play a significant role (Garrote et al., 2008). In the ST reactor, for both treatments, lignin was similar to the initial samples, and it increased significantly with temperature (around $60 \%$ at $165^{\circ} \mathrm{C}$ and $71 \%$ at $180{ }^{\circ} \mathrm{C}$ ). In this case there was no explosion step, so the lignin solubilization was very limited. As it was commented for SET, the increase in lignin with temperature must be related to the higher degree of seed hydrolysis at $180^{\circ} \mathrm{C}$ than at $165^{\circ} \mathrm{C}$ (Table 2) and to the repolymerization and cross-reactions of lignin.

NCS also varied with treatments because the hydrothermal treatments lead to a high solubilization of hemicelluloses (Fernandez-Bolaños et al., 2001). In the SET reactor, the FCs were significantly richer in NCS when treated at $180{ }^{\circ} \mathrm{C}$ than at $200{ }^{\circ} \mathrm{C}$, and, except for Smeti at $180{ }^{\circ} \mathrm{C}$, there was no difference due to variety. When both reactors were compared, ST at $165{ }^{\circ} \mathrm{C}$ led to a similar NCS content (9.99\%) than that of SET at $200{ }^{\circ} \mathrm{C}$, and FC obtained after the $180^{\circ} \mathrm{C} 30^{\prime}$ process had even less NCS (4.86\%). Their composition was studied by gas chromatography and the results are presented in Fig. 2, Subfigures B and C (for SET only Garen Gaze has been shown because no difference was found among varieties). When comparing these graphs with that of fresh flesh (Subfigure A) an important decrease in glucose was found. This sugar could be solubilized into the liquid fraction obtained during the treatments, but also transformed to hydroxymethylfurfural due to the thermal process. This aromatic compound was identified in large amounts in all liquid samples (unpublished data). The FCs were richer in xylose, as it was the main sugar quantified in date dietary fiber (Mrabet et al., 2012). Besides this decrease in glucose, a decrease in xylose and an increase in mannose were observed between treatments at $180{ }^{\circ} \mathrm{C}$ and $200{ }^{\circ} \mathrm{C}$ (Subfigure B). As mentioned for glucose, xylose could also be released into treatment liquors as a soluble sugar or decomposed to furfural, which was also identified in liquids and in the volatile fraction (unpublished data). The increase in mannose could be related to a higher degree of hydrolysis of the seeds in the $200^{\circ} \mathrm{C}$ samples than in the $180^{\circ} \mathrm{C}$ ones (Table 2), since mannose was the major sugar in the seeds (Subfigure A). Comparing reactors (Subfigures B and C), SET at $200{ }^{\circ} \mathrm{C}$ was very similar to ST at $165^{\circ} \mathrm{C}$, where glucose, mannose and xylose were in the same proportion. In the ST treatment at $180{ }^{\circ} \mathrm{C}$, glucose accounted for more than $80 \%$, showing an important solubilization and/or degradation of sugars.

Cellulose did not change significantly because of treatment or variety in the SET reactor, its content varied from 14 to $19 \%$. In ST, the increase in temperature led to a loss in cellulose content. However, in all cases its content was higher in solids after treatment than in the fresh date (about $4 \%$ when calculated on dry and soluble sugar-free basis). Hydrothermal treatments lead to enrichment in cellulose (among other components) in the recovered solid (Fernández-Bolaños et al., 2004; Garrote et al., 2008). Besides, the partial hydrolysis of seeds, whose content in cellulose was higher than that of flesh (Table 1), could also contribute to the increase in the percentage of cellulose.

Fat varied from 5 to $11 \%$ in SET samples, only Smeti at $200{ }^{\circ} \mathrm{C}$ being significantly higher than others. In both ST assays, fat was around $6 \%$ and there was no difference between them either. When comparing with fresh flesh, this enrichment in fat must be due to the partial disorganization of date seeds, much richer in fat than the flesh (Table 1$)$. The soluble sugar content was very low $(0.07-2 \%)$, neither variety nor treatment having significant influence. The protein content was similar in all the samples (9-13\%), only FC from Garen Gaze at $200{ }^{\circ} \mathrm{C}$ was significantly different. Uronic acids decreased the most with treatments and even disappeared in some samples. In ST solids, they were more abundant than in the others.

Phenols increased in all samples when compared with date fruits. In SET, increasing treatment temperatures led to a significant raise in this component. The $\mathrm{FC}$ from the treatment at $165^{\circ} \mathrm{C}$ in the ST reactor had a phenol percentage similar to that of $180{ }^{\circ} \mathrm{C}$ in the SET reactor. A temperature increase in the ST did not imply significant changes in phenols.

For SET, the factorial ANOVA analysis concluded that the factor variety had influence only on fat and uronic acids, and the factor treatment affected the cited components plus lignin, NCS and phenols. There was no interaction between both factors in any case. Therefore, treatment was the most influential factor, and this is the reason why it was decided to study different ST treatment conditions with samples consisting of a variety blending. Besides, this could increase the efficiency from an industrial point of view. 


\subsection{Functional properties and antiradical activity}

WHC, OHC and SOL were measured in all the FCs (Table 4). In the SET reactor, these three parameters showed few differences. WHC was around $6 \mathrm{~mL} / \mathrm{g}$, OHC higher than $8 \mathrm{~mL} / \mathrm{g}$, and SOL about $20 \%$. After factorial ANOVA, it could be concluded that variety or temperature did not have any effect. Only in SOL, lower treatment temperature led to significantly higher SOL values. The same effect of temperature was observed in the ST reactor, but in this case the three properties were affected. WHC, SOL and OHC decreased by increasing the temperature from $165{ }^{\circ} \mathrm{C}$ to $180{ }^{\circ} \mathrm{C}$. Significantly higher values of WHC were obtained with the ST than with the SET one. The opposite results were found for OHC.

Comparing these results with those obtained from fresh date fiber (Mrabet el al, 2012), hydrothermal treatments led to a decrease in WHC and an increase in OHC (12-13 mL water/g fresh date fiber and 3-4 $\mathrm{mL}$ oil $/ \mathrm{g}$ fresh date fiber). Despite the decrease in WHC, the obtained values are in the range of other agricultural byproducts proposed as valuable dietary fiber sources, such as pear pomace, $5 \mathrm{~mL}$ water/g (Mckee \& Latner, 2000) and grapefruit peel, $8.5 \mathrm{~mL}$ water/g (Larrauri, Rupérez, Borroto, \& Saura-Calixto, 1997). Of great interest was the high value of $\mathrm{OHC}$ which was similar to the highest values found in the bibliography, $5-8 \mathrm{~mL} / \mathrm{g}$ for asparagus byproduct (Fuentes-Alventosa et al., 2009). These results for WHC and $\mathrm{OHC}$ make date FC valuable as texture or viscosity modifier. Its use would be also appropriate in food products that require emulsifying properties.

Nowadays, the antioxidant activity of a food ingredient is a very interesting property for the formulation of healthier foods. The secondary date varieties studied in this work were chosen due to their high antioxidant activity linked to dietary fiber (Mrabet et al., 2012). In fact, the antiradical activity presented in Table 1 was constituted in a percentage higher than $90 \%$ by the ethanolinsoluble fraction for the three varieties (data not shown). Both hydrothermal treatments increased the total antiradical activity (Table 4), being even higher than that quantified in date seeds (Table 1) in most cases. A percentage between 60 and $80 \%$ of the FC antiradical capacity was due to the soluble fraction, unlike quantified for fresh flesh and seeds. In FCs, this activity could be due to soluble antioxidant compounds as alcohols, aldehydes, ketones, benzoic and cinnamic acids (Conde, Moure, Domínguez, \& Parajó, 2011) derived from non-cellulosic structural components of date fruits, including lignin and hemicelluloses. In SET, activity increased significantly with temperature in both soluble and insoluble fractions. The opposite behavior was found in ST, where activity decreased with temperature. The influence of hydrothermal treatment parameters were also noticed by González, Cruz, Domínguez, and Parajó (2004) and Garrote et al. (2008) working with eucalyptus wood and barley husks respectively. These authors concluded that treatments at higher severities led to extracts with decreased antioxidant activity, suggesting a different nature and/or structure of the active compounds. The factorial ANOVA analysis concluded that the variety was also a significant factor for SET soluble activity, but not for the insoluble one. FCs from Eguwa were the samples with the highest soluble antiradical activity (360 and $447 \mathrm{mmol} \mathrm{TE} / \mathrm{Kg}$ for $180^{\circ} \mathrm{C}$ and $200^{\circ} \mathrm{C}$, respectively). This variety had also the highest activity in its fresh seeds (Table 1 ), so their partial disorganization due to treatments could probably lead to FCs with higher antioxidant activity. When both reactors were compared, there were significant differences only in the soluble antiradical activity, being lower in FCs obtained by ST. The total activity for date FC varied from 240 to $580 \mathrm{mmol} \mathrm{TE} / \mathrm{Kg}$. It could be hardly found in bibliography agricultural by-products with so high antioxidant activity. Only citrus by-products (Marín, Soler-Rivas, Benavente-García, Castillo, \& Pérez-Álvarez, 2007) and red grape pomace (Llobera \& Cañellas, 2007) were reported to have similar antioxidant activity to date FC, 70-240 and $427 \mathrm{mmol} \mathrm{TE} / \mathrm{Kg}$ respectively. This fact is of great interest for a possible application of date FC as food ingredient.

The changes observed in this property were very similar to those above commented for phenols (Table 1). In fact, a regression analysis between phenols and soluble antiradical activity showed $r^{2}$ value of 0.8617 for a linear model, showing in this way that both parameters were highly related.

\subsection{Comparative study between reactors}

The SET reactor has the technological advantage of the disruption of lignocellulosic material due to the explosive decompression. However, this treatment is hardly applied by the industry due to its high working pressure (up to $42 \mathrm{~kg} / \mathrm{cm}^{2}$ ). The ST reactor works at lower pressure (up to $9 \mathrm{~kg} / \mathrm{cm}^{2}$ ) which is easily reached by industrial steam generators. In this other reactor, longer treatment periods have similar effects to explosive decompression when working with materials which are not very lignified. When date fruits were processed, the recovery of the solid residue was similar (Table 2), but important differences were found in granulometry. As was expected, the percentage of solid with a size lower than $4 \mathrm{~mm}$ was higher in SET than in ST, and in treatments with higher temperatures. However, the hardness of pieces with size higher than $4 \mathrm{~mm}$ was lower in the ST reactor which implies an advantage in the milling of the recovered solid and, therefore, promotes its use as active carbon,

Table 4

Functional Properties and Antiradical Activity (mmol TE/Kg dry weight) of FCs after Hydrothermal Treatments.

\begin{tabular}{|c|c|c|c|c|c|c|}
\hline & & \multirow[t]{2}{*}{ WHC mL/g } & \multirow[t]{2}{*}{$\% \mathrm{SOL}$} & \multirow[t]{2}{*}{$\mathrm{OHC} \mathrm{mL/g}$} & \multicolumn{2}{|l|}{ Antiradical activity } \\
\hline & & & & & Soluble & Insoluble \\
\hline \multirow[t]{2}{*}{ GG } & $180^{\circ} \mathrm{C}, 5^{\prime} \mathrm{SET}$ & $5.37 \pm 0.65 \mathrm{a}$ & $22.71 \pm 0.92 \mathrm{a}$ & $8.70 \pm 0.31 \mathrm{a}$ & $206.84 \pm 8.33 a$ & $93.06 \pm 1.14 \mathrm{~b}$ \\
\hline & $200^{\circ} \mathrm{C}, 5^{\prime} \mathrm{SET}$ & $5.88 \pm 0.17 \mathrm{ab}$ & $23.28 \pm 2.46 \mathrm{a}$ & $8.68 \pm 0.15 a$ & $264.35 \pm 4.47 b$ & $131.96 \pm 3.19 c$ \\
\hline \multirow[t]{2}{*}{ EG } & $180^{\circ} \mathrm{C}, 5^{\prime} \mathrm{SET}$ & $6.28 \pm 0.26 b$ & $22.55 \pm 2.46 \mathrm{a}$ & $8.32 \pm 0.60 a$ & $360.24 \pm 43.64 c$ & $65.30 \pm 6.03 a$ \\
\hline & $200^{\circ} \mathrm{C}, 5^{\prime} \mathrm{SET}$ & $5.97 \pm 0.28 \mathrm{ab}$ & $19.88 \pm 2.45 \mathrm{a}$ & $8.74 \pm 0.89 a$ & $446.77 \pm 29.52 \mathrm{~d}$ & $138.25 \pm 18.93 c$ \\
\hline \multirow[t]{2}{*}{ SM } & $180^{\circ} \mathrm{C}, 5^{\prime} \mathrm{SET}$ & $5.68 \pm 0.76 \mathrm{ab}$ & $32.32 \pm 2.79 \mathrm{~b}$ & $8.09 \pm 0.97 a$ & $198.24 \pm 25.70 a$ & $79.46 \pm 5.90 a b$ \\
\hline & $200^{\circ} \mathrm{C}, 5^{\prime} \mathrm{SET}$ & $6.27 \pm 0.35 b$ & $19.67 \pm 2.77 \mathrm{a}$ & $7.62 \pm 0.46 a$ & $277.34 \pm 6.56 b$ & $101.25 \pm 6.98 b$ \\
\hline \multicolumn{2}{|c|}{ Average } & $5.91^{*}$ & $23.40^{*}$ & $8.35^{*}$ & $292.30^{*}$ & $101.55^{*}$ \\
\hline \multicolumn{2}{|c|}{$165^{\circ} \mathrm{C}, 30^{\prime} \mathrm{ST}$} & $8.50 \pm 0.43 \mathrm{~B}$ & $24.75 \pm 0.71 \mathrm{~B}$ & $7.06 \pm 0.67 \mathrm{~B}$ & $184.90 \pm 3.57 \mathrm{~B}$ & $127.29 \pm 11.88 \mathrm{~B}$ \\
\hline \multicolumn{2}{|c|}{$180^{\circ} \mathrm{C}, 30^{\prime} \mathrm{ST}$} & $6.01 \pm 0.52 \mathrm{~A}$ & $20.14 \pm 1.45 \mathrm{~A}$ & $6.03 \pm 0.25 \mathrm{~A}$ & $150.07 \pm 13.79 \mathrm{~A}$ & $90.39 \pm 10.31 \mathrm{~A}$ \\
\hline \multicolumn{2}{|c|}{ Average } & $7.25^{* *}$ & $22.44^{*}$ & $6.55^{* *}$ & $167.48^{* *}$ & $108.84^{*}$ \\
\hline
\end{tabular}

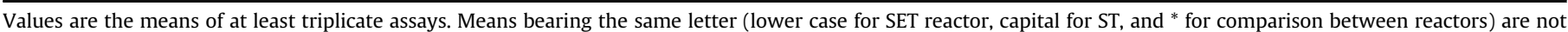
significantly different at the $5 \%$ level as determined by the Duncan multiple-range test.

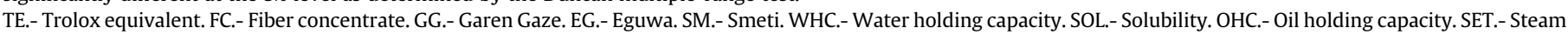
explosion treatment. ST.- Steam treatment. 
animal feeding, abrasive or in cosmetic formulations as an exfoliating agent (Al-Muhtaseb, 2010; Rodríguez et al., 2008).

FCs from both reactors showed significant differences in composition (Table 3). Those from the ST were richer in lignin and uronic acids, but poorer in NCS and phenols. Their soluble antiradical activity was lower too. The treatment at $165^{\circ} \mathrm{C}$ for 30 min led to an FC with a composition which was very similar to that of the FCs obtained with the SET reactor. Smoother treatments (at lower temperature or shorter than $30 \mathrm{~min}$ ) could improve the composition and antiradical activity. The functional properties were affected by the treatment: WHC increased in the ST reactor, but OHC decreased. Just as it happened for composition, the FC from the treatment at $165^{\circ} \mathrm{C}$ had better values than that from $180^{\circ} \mathrm{C}$.

The ST at optimized conditions of secondary varieties of Tunisian date fruits could be an interesting alternative for date growers, because this reactor could be easily scaled up. The obtained FCs have similar chemical composition and functional characteristic to those obtained by SET, and they could be a valuable ingredient for the formulation of healthier foods (fiber or antioxidant enriched). They have a balanced nutritional composition (around 6\% fat, 10\% protein, and 70-80\% dietary fiber). Date seed oil has been studied by other authors, and its composition in vitamins, minerals and fatty acids made it valuable for food formulation (Habib \& Kamal, 2013; Nehdi et al, 2010). Besbes et al. (2005) studied the effects of heating on date seed oil and they concluded that this oil resisted thermal treatment during a long period of time (30-40 h). So, it is probable that the oil from FCs had good quality parameters. Besides, these FCs have very high antioxidant activity, similar to the highest antioxidant agricultural by-products (Llobera \& Cañellas, 2007; Marín et al., 2007), citrus by-products and Manto Negro red grape pomace. The pleasant chocolate/coffee flavor of the solids is another positive characteristic for their use in food formulation, especially in dairy or bakery products. It would be necessary to adjust the ST conditions to optimize the composition, balance of components, and antioxidant activity, but this is a promising process for valorization of Tunisian secondary date varieties which will help in the industry of the production areas. The use of the secondary date varieties in the food industry as healthy ingredients could also help in the fight against the reduction in vegetable genetic variability. In this way, the growth of these native cultivars from the Tunisian coastal oasis for technological purposes may play an important role in the economical, social and ecological level of the people from this developing region.

\section{Acknowledgments}

This research was supported by the Ministerio de Asuntos Exteriores y Cooperación - Agencia Española de Cooperación Internacional para el Desarrollo MAEC-AECID REF. 550352 (Spain), and by the Banq Islamique de Développement BID (Saudi Arabia REF. 36/11201707).

\section{References}

Al-Farsi, M. A. (2003). Clarification of date juice. International Journal of Food Science and Technology, 38, 241-245.

Al-Muhtaseb, S. A. (2010). Adsorption and desorption equilibria of nitrogen, methane, ethane, and ethylene on date-pit activated carbon. Journal of Chemical and Engineering Data, 55, 313-319.

Besbes, S., Blecker, C., Deroanne, C., Lognay, G., Drira, N., \& Attia, H. (2005). Heating effects on some quality characteristics of date seed oil. Food Chemistry, 91, 469-476.

Chibane, H., Benamara, S., Noui, Y., \& Djouad, A. (2007). Some physicochemical and morphological characterizations of three varieties of Algerian common date. European Journal of Scientific Research, 18, 134-140.
Conde, E., Moure, A., Domínguez, H., \& Parajó, J. C. (2011). Production of antioxidants by non-isothermal autohydrolysis of lignocellulosic wastes. LWT-Food Science and Technology, 44, 436-442.

Elleuch, M., Besbes, S., Roiseux, O., Blecker, C., Deroanne, C., Drira, N. E., et al. 2008). Date flesh: chemical composition and characteristics of the dietary fibre. Food Chemistry, 111, 676-682 (This reference is a complete description of two edible date varieties, and it is important as a comparison with the inedible varieties studied in this work).

Fernandez-Bolaños, J., Felizón, B., Heredia, A., Rodríguez, R., Guillén, R., \& Jiménez, A. (2001). Steam-explosion of olive stones: hemicelluloses solubilization and enhancement of enzymatic hydrolysis of cellulose. Bioresource Technology, 79, 53-61 (In this key reference there is a complete description of the steam explosion treatment applied in the present work).

Fernández-Bolaños, J., Rodríguez, G., Gómez, E., Guillén, R., Jiménez, A., \& Heredia, A. (2004). Total recovery of the waste of two-phase olive oil processing: isolation of added-value compounds. Journal of Agricultural and Food Chemistry, 52, 5849-5855.

Fuentes-Alventosa, J. M., Rodríguez-Gutiérrez, G., Jaramillo-Carmona, S., EspejoCalvo, J. A., Rodríguez-Arcos, R., Fernández-Bolaños, J., et al. (2009). Extraction method on phytochemical composition and antioxidant activity of high dietary fibre powders obtained from asparagus byproducts. Food Chemistry, 116, 484-490.

Garrote, G., Cruz, J. M., Domínguez, H., \& Parajó, J. C. (2008). Non-isothermal autohydrolysis of barley husks: product distribution and antioxidant activity of ethyl acetate soluble fractions. Journal of Food Engineering, 84, 544-552.

González, J., Cruz, J. M., Domínguez, H., \& Parajó, J. C. (2004). Production of antioxidants from Eucaliptus globulus wood by solvent extraction of hemicelluloses hydrolysates. Food Chemistry, 84, 243-251.

Habib, H. M., \& Kamal, H. (2013). Carotenoids, fat soluble vitamins and fatty acid profiles of 18 varieties of date seed oil. Industrial Crops and Products, 42, 567-572.

Ishrud, O., Zahid, M., Ahmad, V. U., \& Pan, Y. (2001). Isolation and structure analysis of a glucomannan from the seeds of Lybian dates. Journal of Agricultural and Food Chemistry, 49, 3772-3774.

Jiménez, A., Rodríguez, R., Fernández-Caro, I., Guillén, R., Fernández-Bolaños, J., \& Heredia, A. (2000). Dietary fibre content of tables olives processed under different European styles: study of physicochemical characteristics. Journal of the Science of Food and Agriculture, 87, 1-6.

Kar, W. E., Gutiérrez, C. V., \& Kinoshita, C. M. (1998). Steam explosion of sugarcane bagasse as a pretreatment for conversion to ethanol. Biomass and Bioenergy, 14, 1-9.

* Lama-Muñoz, A., Rodriguez-Gutierrez, G., Rubio-Senent, F., Gómez-Carretero, A., \& Fernández-Bolaños, J. (2011). New hydrothermal treatment of alperujo enhances the content of bioactive minor components in crude pomace olive oil. Journal of Agricultural and Food Chemistry, 59, 1115-1123. In this key reference there is a complete description of the steam treatment (ST) applied in the present manuscript.

Larrauri, J. A., Rupérez, P., Borroto, B., \& Saura-Calixto, F. (1997). Seasonal changes in the composition and properties of a high dietary fibre powder from grapefruit peel. Journal of the Science of Food and Agriculture, 74, 308-312.

Llobera, A., \& Cañellas, J. (2007). Dietary fibre content and antioxidant activity of Manto Negro red grape (Vitis vinifera): pomace and stem. Food Chemistry, 101, 659-666.

Marín, F. R., Soler-Rivas, C., Benavente-García, O., Castillo, J., \& Pérez-Álvarez, J. A. (2007). By-products from different citrus processes as a source of customized functional fibres. Food Chemistry, 100, 736-741.

Mckee, L. H., \& Latner, T. A. (2000). Underutilized sources of dietary fiber: a review. Plant Foods for Human Nutrition, 55, 285-304.

Montane, D., Farriol, X., \& Salvado, J. (1998). Fractionation of wheat straw by steam explosion pretreatment and alkali delignification, cellulose pulp and byproducts from hemicellulose and lignin. Journal of Wood Chemistry and Technology, 18, 171-191.

* Mrabet, A., Rodríguez-Arcos, R., Guillén-Bejarano, R., Chaira, N., Ferchichi, A., \& Jiménez-Araujo, A. (2012). Dietary fiber from Tunisian common date cultivars (Phoenix dactylifera L.): chemical composition, functional properties, and antioxidant capacity. Journal of Agricultural and Food Chemistry, 60, 3658-3664 (This is a comparative study of ten secondary date varieties. Authors identify some varieties worthy to be valorised as source of healthy food ingredients. These varieties were studied in the present work).

* Nehdi, I., Omri, S., Khalil, M. I., \& Al-Resayes, S. I. (2010). Characteristics and chemical composition of date palm (Phoenix canariensis) seeds and seed oil. Industrial Crops and Products, 32, 360-365 (This reference is a very complete work about date seeds and date seed oil. It is important in the discussion about composition and possible uses of date seeds).

Rodríguez, G., Lama, A., Rodríguez, R., Jiménez, A., Guillén, R., \& FernándezBolaños, J. (2008). Olive stone an attractive source of bioactive and valuable compounds. Bioresource Technology, 99, 5261-5269.

Rodríguez, R., Jaramillo, S., Rodríguez, G., Espejo, J. A., Guillén, R., FernándezBolaños, J., et al. (2005). Antioxidant activity of ethanolic extracts from several asparagus cultivars. Journal of Agricultural and Food Chemistry, 53, 5212-5217.

Rodríguez-Gutiérrez, G., Lama-Muñoz, A., Ruiz-Méndez, M. V., Rubio-Senent, F., \& Fernández-Bolaños, J. (2012). New olive-pomace oil improved by hydrothermal pre-treatments. In B. Dimitrios (Ed.), Olive oil-constituents, quality, health properties and bioconversions (pp. 249-266). In Tech, ISBN 978-953307-921-9. 